H. Reinhardt $\cdot$ M. Kriews $\cdot$ H. Miller $\cdot$ O. Schrems

C. Lüdke • E. Hoffmann · J. Skole

\title{
Laser ablation inductively coupled plasma mass spectrometry: a new tool for trace element analysis in ice cores
}

Received: 9 January 2001 / Revised: 19 March 2001 / Accepted: 22 March 2001

\begin{abstract}
A new method for the detection of trace elements in polar ice cores using laser ablation with subsequent inductively coupled plasma mass spectrometry analysis is described. To enable direct analysis of frozen ice samples a special laser ablation chamber was constructed. Direct analysis reduces the risk of contamination. The defined removal of material from the ice surface by means of a laser beam leads to higher spatial resolution (300$1000 \mu \mathrm{m}$ ) in comparison to investigations with molten ice samples. This is helpful for the detection of element signatures in annual layers of ice cores. The method was applied to the successful determination of traces for the elements $\mathrm{Mg}, \mathrm{Al}, \mathrm{Fe}, \mathrm{Zn}, \mathrm{Cd}, \mathrm{Pb}$, some rare-earth elements (REE) and minor constituents such as $\mathrm{Ca}$ and $\mathrm{Na}$ in ice cores. These selected elements serve as tracer elements for certain sources and their element signatures detected in polar ice cores can give hints to climate changes in the past. We report results from measurements of frozen ice samples, the achievable signal intensities, standard deviations and calibration graphs as well as the first signal progression of ${ }^{208} \mathrm{~Pb}$ in an 8,000 -year-old ice core sample from Greenland. In addition, the first picture of a crater on an ice surface burnt by an IR laser made by cryogenic scanning electron microscopy is presented.
\end{abstract}

\section{Introduction}

The snow and ice shields of the polar regions serve as a climate archive and provide useful insight back to about 250,000 years of Earth climate history $[1,2]$. In these last

Dedicated to Dr. habil. Hans-Joachim Dietze on the occasion of his 65 th birthday

H. Reinhardt · M. Kriews ( $(\mathbb{}) \cdot$ H. Miller · O. Schrems Alfred Wegener Institute for Polar and Marine Research, Am Handelshafen 12, 27570 Bremerhaven, Germany e-mail: mkriews@awi-bremerhaven.de

C. Lüdke $\cdot$ E. Hoffmann $\cdot$ J. Skole Institute for Spectrochemistry and Applied Spectroscopy, Albert-Einstein-Strasse 9, 12489 Berlin, Germany natural "clean air" areas on Earth, researchers are able to examine the natural atmosphere without or with little anthropogenic influence. Every year about $60-350 \mathrm{~kg} \mathrm{~m}^{-2}$ precipitation is deposited as snow in the polar regions and therewith dust particles and gaseous inclusions are conserved for thousands of years. Polar ice cores contain information about the atmosphere of the past, temperature, precipitation, trace gas concentration and the chemical composition of inclusions. The aim of the investigation reported here was to establish a new method for the determination of trace elements in ice cores from polar regions with laser ablation inductively coupled plasma mass spectrometry (LA-ICP-MS). A cryogenic chamber for LA of ice samples was constructed and the analysis system was optimized for the ice matrix.

Advantages of the new LA-ICP-MS application

LA-ICP-MS offers the possibility of direct analysis of deep frozen ice core samples from polar regions. The main advantages are

- Low risk of contamination in comparison to conventional solution ICP-MS.

- A high spatial resolution from 300 to $1000 \mu \mathrm{m}$ (recording of depth profile) dependent on the spot size of the laser crater.

With such a high spatial resolution it is possible to detect seasonal variations of the element distribution and also the composition in the low-lying ice layers where annual layers have a thickness of only about $1 \mathrm{~mm}$. In order to obtain time-resolved measurements, with respect to the age of the ice, it is necessary to probe such thin layers. Here, the LA-ICP-MS system is the first one which fulfills this requirement. Up to now, element analytical determinations of ice core samples were only possible with molten ice. After a special sample preparation including enrichment procedures and addition of reagents, the samples were analyzed with physicochemical methods. For example Kriews et al. [3] and Matoba et al. [4] presented a determination 
of trace elements at nanogram per kilogram levels with a desolvated microconcentric nebulizer (MCN 6000) in combination with ICP-MS with a $2 \mathrm{~mL}$ sample from an ice core. Since concentrations in such ice samples are very low (nanograms per kilogram), the risk of contamination during sample preparation is very high. Owing to the need for relatively large volumes in solution analysis, only a small spatial (centimeter level) and, therefore, a reduced temporal resolution of molten ice core samples is possible.

Tracer elements in ice cores

The distribution and composition of trace elements in annual layers of ice cores can, for example, provide information about the changes from cold to warm periods [e.g., increase of mineral dust (Al, Fe, REE) or sea salt ( $\mathrm{Na}, \mathrm{Mg})]$, special events in Earth history, such as volcanic eruptions (dust horizons in ice core layers), or point to sources of mineral dust $[5,6,7]$. The detection of seasonal variations of mineral dust and sea salt concentrations can give valuable hints for the dating of the ice cores.

Sodium and magnesium are tracer elements for sea salt; aluminium and iron as well as REE are mineral dust tracers. The sea salt and the mineral dust concentrations in arctic snow and ice samples vary with the season. Owing to the progression of the polar front during summer and winter, air masses bring more or less sea salt or mineral dust into the Arctic and these are deposited on snow and ice. Lead, zinc and cadmium are tracers for anthropogenic sources or are indicators of contamination effects. The concentrations of these elements can also show seasonal variations.

\section{Experimental}

Experimental setup

The experimental setup for the direct analysis of deep frozen ice samples by LA-ICP-MS is illustrated in Fig. 1.

\section{Laser system}

For many applications the use of UV wavelengths (e.g., $266 \mathrm{~nm}$ ) for LA is more suitable because UV radiation can be focused to a smaller spot than longer wavelength radiation and because it is absorbed more strongly by many materials than visible and IR laser radiation [8]. The absorption coefficient of ice at UV wavelengths is about a factor of 100-10,000 lower than at 1,064 $\mathrm{nm}$ [9], i.e., ice is more translucent and less material would be ablated. Thus, the laser used was a modified Nd:YAG (DCR-11, Spectra Physics) which operates at $1,064 \mathrm{~nm}$. A power meter and an aperture system were installed behind the beam exit to control the laser energy and the spot size.

\section{Sample alignment}

For an exact alignment of the sample inside the LA chamber, a diode laser (red) is integrated on the optical axis of the Nd:YAG laser beam. With support of a charge-coupled-device (CCD) color camera the laser beam is focused on the sample surface and the $a b$ lation process can be observed.

\section{LA chamber}

To enable the direct analysis of solid ice samples at a temperature of $-30{ }^{\circ} \mathrm{C}$ a special LA chamber was constructed [10]. The standard temperature for the storage of ice core samples is $-30^{\circ} \mathrm{C}$ because no changes inside the ice take place at these low temperatures. The chamber has a large volume (diameter: $13 \mathrm{~cm}$, height: $5 \mathrm{~cm}$ ) to enable the measurement of ice core samples cut as discs (diameter: $10 \mathrm{~cm}$ ) or segments with one or more annual layers depending on the depth of the ice origin. The inner part of the chamber consists of high-purity copper and contains a cooling canal for the cooling liquid (silicon oil). The outer shell consists of Teflon, which provides good insulation against the copper block. The carrier gas (argon) is cooled to avoid the formation of water droplets at the optical window and to prevent melting processes at the sample surface during the ablation process. A computer controls the sample stage of the LA chamber in an $x y z$ orientation as well as the laser system.

\section{ICP-MS system}

Measurements were carried out using an ELAN 6000 quadrupolebased ICP-MS system from PerkinElmer/Sciex. An argon flow rate of $0.9 \mathrm{Lmin}^{-1}$ carries the ablated material into the plasma (tube
Fig. 1 Experimental setup for the laser ablation of solid ice samples

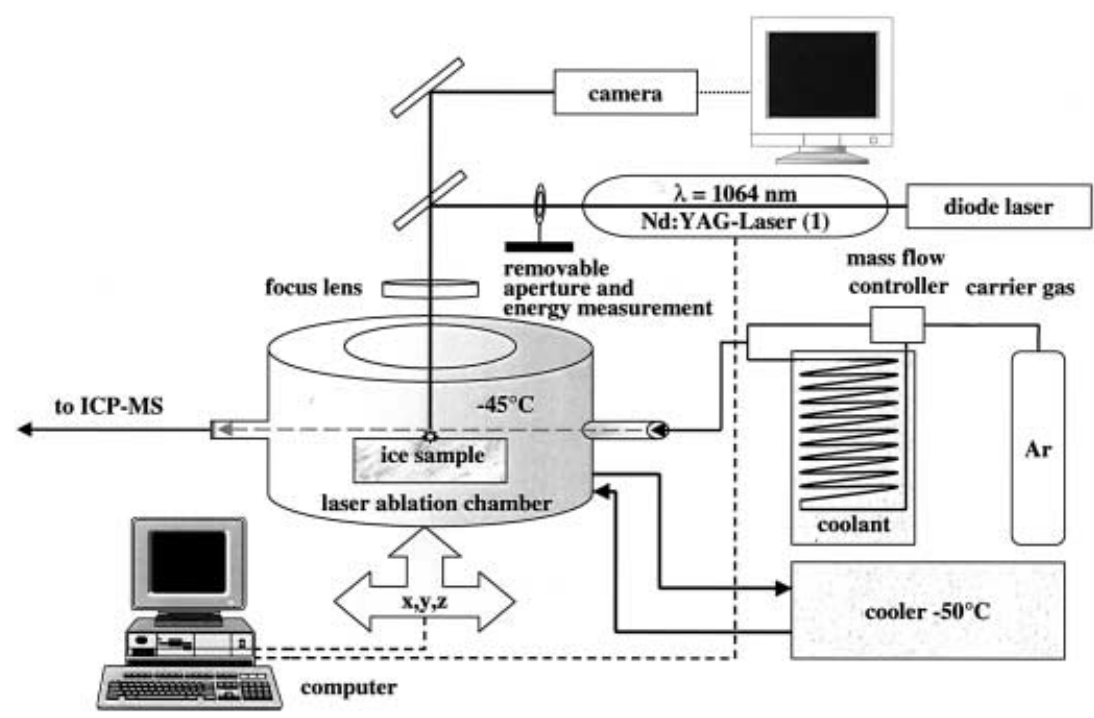


Table 1 Operating conditions for the inductively coupled plasma mass spectrometry system

\begin{tabular}{ll}
\hline $\begin{array}{l}\text { Inductively coupled } \\
\text { plasma mass spectrometer }\end{array}$ & PerkinElmer Sciex Elan 6000 \\
\hline Radio frequency power & $1300 \mathrm{~W}$ \\
Plasma gas & $15 \mathrm{Lmin}^{-1}$ \\
Auxiliary gas & $0.8 \mathrm{Lmin}^{-1}$ \\
Carrier gas & $0.9 \mathrm{Lmin}-1$ \\
Lens setting & Autolens mode on \\
Measuring mode & Peak hopping \\
Isotopes measured & ${ }^{17} \mathrm{OH},{ }^{19} \mathrm{OH},{ }^{23} \mathrm{Na},{ }^{24} \mathrm{Mg},{ }^{27} \mathrm{Al}$, \\
& ${ }^{44} \mathrm{Ca},{ }^{64} \mathrm{Zn},{ }^{103} \mathrm{Rh},{ }^{114} \mathrm{Cd},{ }^{208} \mathrm{~Pb}$, \\
Dwell time & rare-earth elements \\
Detector mode & $10 \mathrm{~ms}$ \\
Settling time & Dual (pulse and analogue) \\
& $1500 \mu \mathrm{s}$
\end{tabular}

Table 2 Operating conditions for the laser system

\begin{tabular}{ll}
\hline PerkinElmer laser sampler 320 & \\
Wavelength & $1064 \mathrm{~nm}$ \\
Mode & Q-switch \\
Q-switch time & $220 \mu \mathrm{s}$ \\
Excitation lamp energy & $60 \mathrm{~J}$ \\
Laser energy & $370 \mathrm{~mJ}$ \\
Pulse frequency & $10 \mathrm{~Hz}$ \\
Laser scan mode & Point, line, area \\
Focus & On sample surface \\
Spot size & $300 \mu \mathrm{m}$ \\
\hline
\end{tabular}

length: $100 \mathrm{~cm}$ ) for ionization and subsequent analysis in the mass spectrometer.

Operating conditions

An overview of the optimized operation parameters used with the ICP-MS system and the Nd:YAG laser is given in Tables 1 and 2.

Preparation of ice standards

A major problem of LA-ICP-MS as a method for quantitative determination is the calibration with matrix-matched standards; therefore, it seems to be an easy task to make a calibration with frozen standard solutions for the quantitative determination in ice samples. Owing to the expected values of the trace elements in ice core samples from the Arctic, low concentration standards of some elements were prepared. An overview of the measured concentrations of heavy metals in three different time periods of the GRIP Greenland ice core $[11,12]$ is given in Table 3. The procedure for the preparation of suitable ice standards with different element concentrations $\left(10 \mathrm{ngkg}^{-1}-100 \mu \mathrm{gkg}^{-1}\right)$ is shown in Fig. 3. Commercially available ICP-MS multielement solutions (PE 1 and PE 2: PerkinElmer) were filled in precooled, purified Petri dishes (diameter: $5 \mathrm{~cm}$, height: $1 \mathrm{~cm}$ ) after dilution and addition of nitric acid at a temperature of $-30^{\circ} \mathrm{C}$ in our ice laboratory. All preparation steps were performed under clean room conditions (US-class 100). The Petri dishes and the sample carrier were run through a special cleaning procedure with different acid basins before use. The cleaning procedure was described in detail by Kriews et al. [13]. To prevent inhomogeneities in ice standards the filling was made step by step to a maximum height of $1 \mathrm{~cm}$. In 5-mL steps the standard solutions were transferred into the Petri dishes to enable a shock freezing of

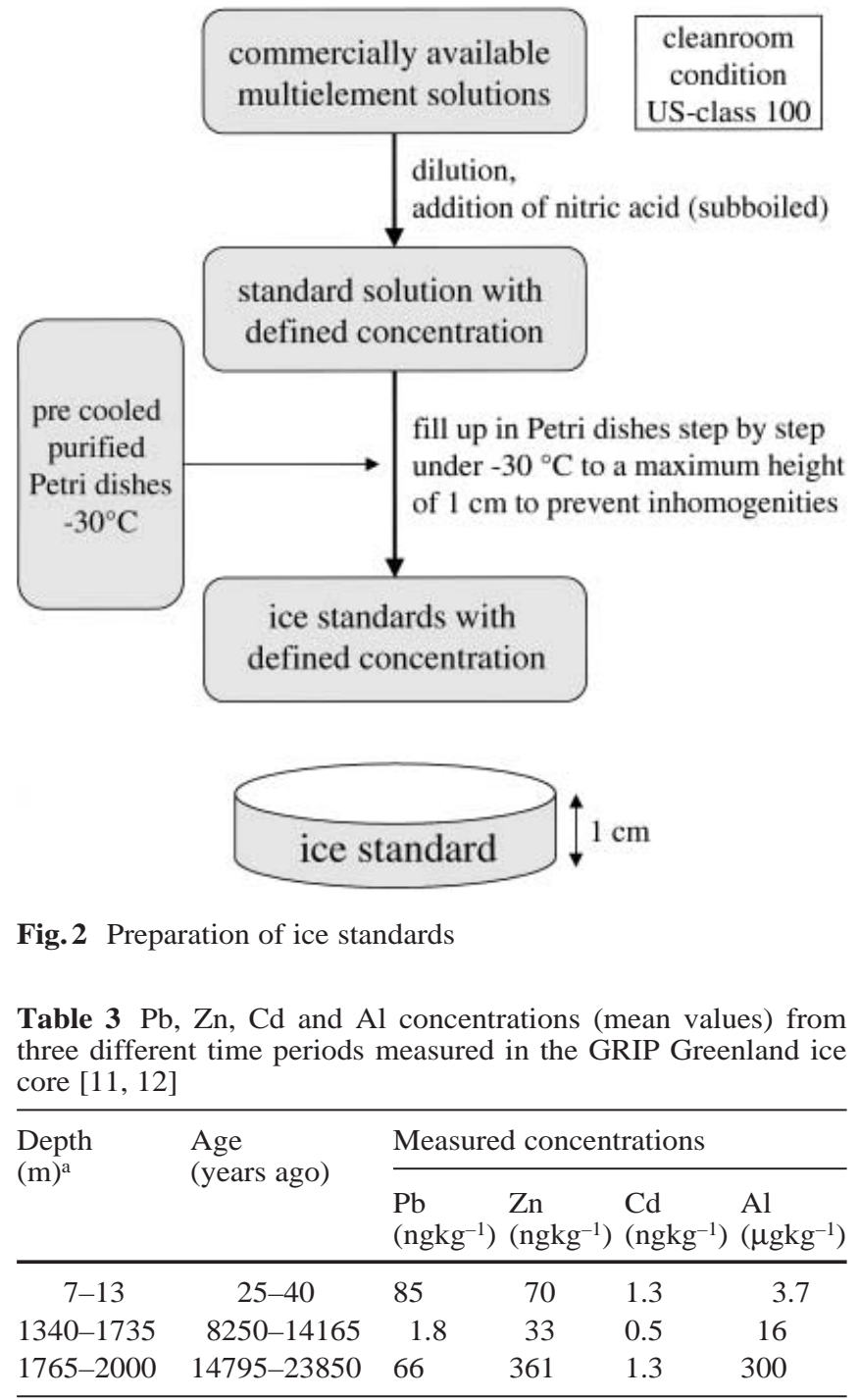

a Surface 1989

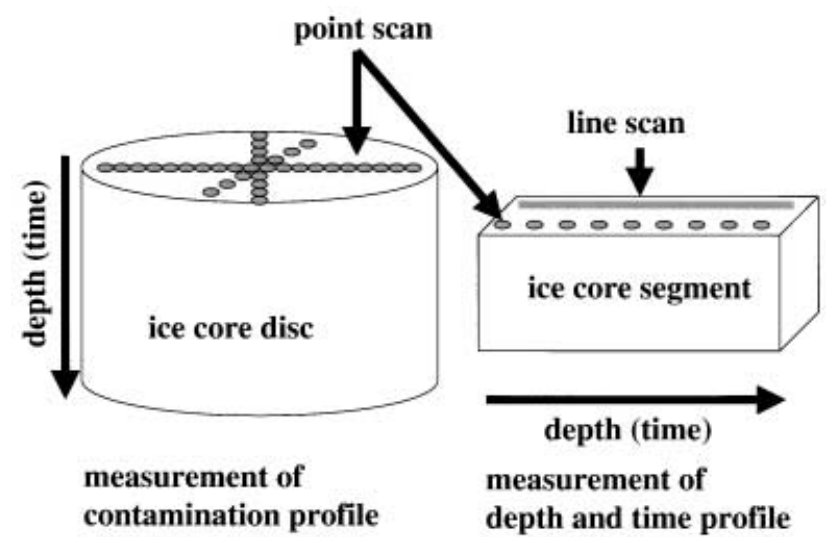

Fig. 3 Different ablation pattern along an ice core disc and an ice core segment

the solution. It seems that, on one hand, an enlarged thickness leads to inhomogeneously frozen samples, whereas a thinner layer is pervious for the laser beam, and the surface of the sample carrier will be hit. Furthermore, it seems that a higher concentrated solution 
(over $100 \mu \mathrm{gkg}^{-1}$ ) leads to strong inhomogeneously frozen ice and results in more unstable signals. This needs to be kept in mind in the calibration of the system. The ice standards were stored under a clean bench at $-30^{\circ} \mathrm{C}$.

Ice sample preparation

\section{Different sample shapes}

There are two possible ways to cut an ice core sample for trace element analysis with LA-ICP-MS: ice core discs or segments (Fig. 3). The cutting of the cores is carried out in an ice laboratory at $-30{ }^{\circ} \mathrm{C}$ under clean room conditions. A ceramic working bench with ceramic knives or knives made of high-purity molybdenum were used. The samples were frozen on object slides and had a maximum thickness of $1 \mathrm{~cm}$. To enable focusing of the laser beam during the measurement, a smooth sample surface is required. The discs had a diameter of $10 \mathrm{~cm}$ and the segments had a length of $10 \mathrm{~cm}$ and a width of $5 \mathrm{~cm}$.

\section{Ablation patterns}

The ice core disc is more suitable for contamination studies than ice core segments. In order to check for contaminations coming from the ice core drill, the point-scan mode was chosen (laser spots move from the rim towards the center). With the point-scan mode, the laser shoots for a certain time at the same spot at the surface of the ice sample. A decontamination procedure for measurements of liquid ice samples with a stepwise melting process was described by Matoba et al. [4]. A full ice core disc with a diameter of $10 \mathrm{~cm}$ could not be measured by LA-ICP-MS because there was not enough sample material available. Legrand and Delmas [2] and Boutron et al. [14] described the contamination of an ice core for several elements including organic compounds. For example, a contamination profile with an enrichment factor of approximately 1,000 for $\mathrm{Pb}$ could be found for the outer part of the ice core; however, concentrations decrease rapidly from the outer to the inner parts of the core. The inner part of the ice core exhibits a plateau corresponding to the part of the core which is free of contamination. The "clean" usable part of the ice core is in most cases reached after 2-3 cm towards the center. The ice samples measured were decontaminated in our ice laboratory prior to the analysis and only samples from the center of the ice core were investigated by LA-ICPMS. The other possible shape of the ice sample is the ice core segment, which is more suitable to study depth profiles. The age and, therefore, the depth of the ice in a segment has a horizontal direction instead of vertical direction in a disc. The point-scan as well as the line-scan mode were used for the segment. In the line-scan mode the laser fires along a defined line.

\section{Results}

Studies of craters in an ice surface burnt with an IR laser

\section{Achievable spot size}

The achievable spatial resolution of the ice core measurement depends on the spot size and the energy of the laser beam. With the help of a beam analyzer a laser beam profile was measured. The beam was focused on an IR CCD camera (COHU solid-state camera) in the near field (same distance as to the ice sample) and was analyzed using a special software program [15]. The software tool calculated a possible spot size of $220 \mu \mathrm{m}$ at $370 \mathrm{~mJ}$ laser energy. An ice sample surface (50-fold magnification) with a crater resulting from 50 laser shots (point-scan mode) with an

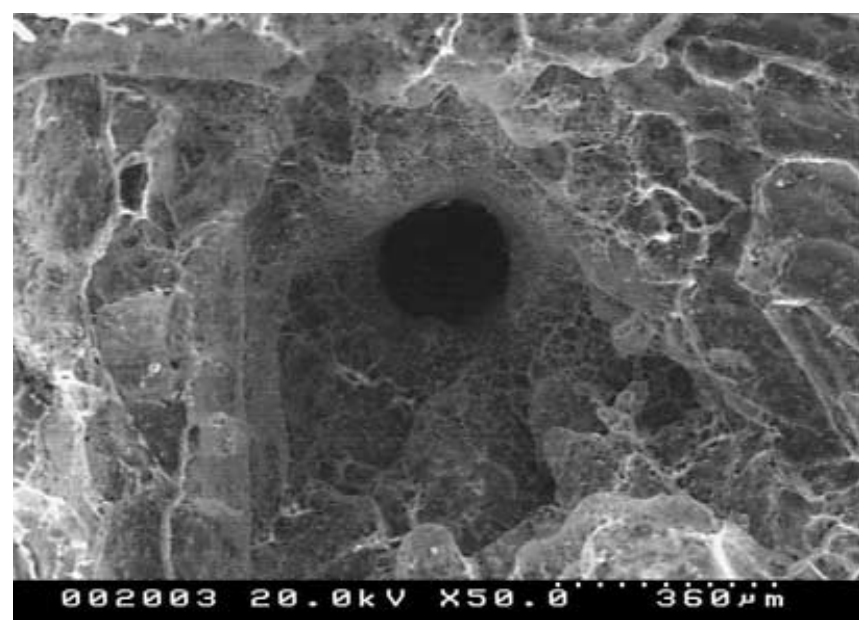

Fig. 4 Cryogenic scanning electron microscopy picture of an ice sample surface with an IR laser crater (50 shots, $370 \mathrm{~mJ}$ )

energy of $370 \mathrm{~mJ}$ is shown in Fig. 4. The picture was made by cryogenic scanning elelectron microscopy (cryo-SEM), a modified SEM coupled with an energy dispersive X-ray analysis (EDXA) system for material examination of building materials as described in Refs. [16, 17]. The surface of the sample was sputtered with carbon and was measured at a temperature of $-130^{\circ} \mathrm{C}$ and an energy of $20 \mathrm{keV}$. The center of the measured crater had a diameter of $216 \mu \mathrm{m}$. In an example with 50 laser shots, the total crater area of melted and refrozen ice had a diameter of about $580 \mu \mathrm{m}$.

\section{Mass of ablated material}

The mass of ablated ice material during a point scan is a function of the laser energy, the number of laser shots and, therefore, of measuring time. The laser beam removes ma-

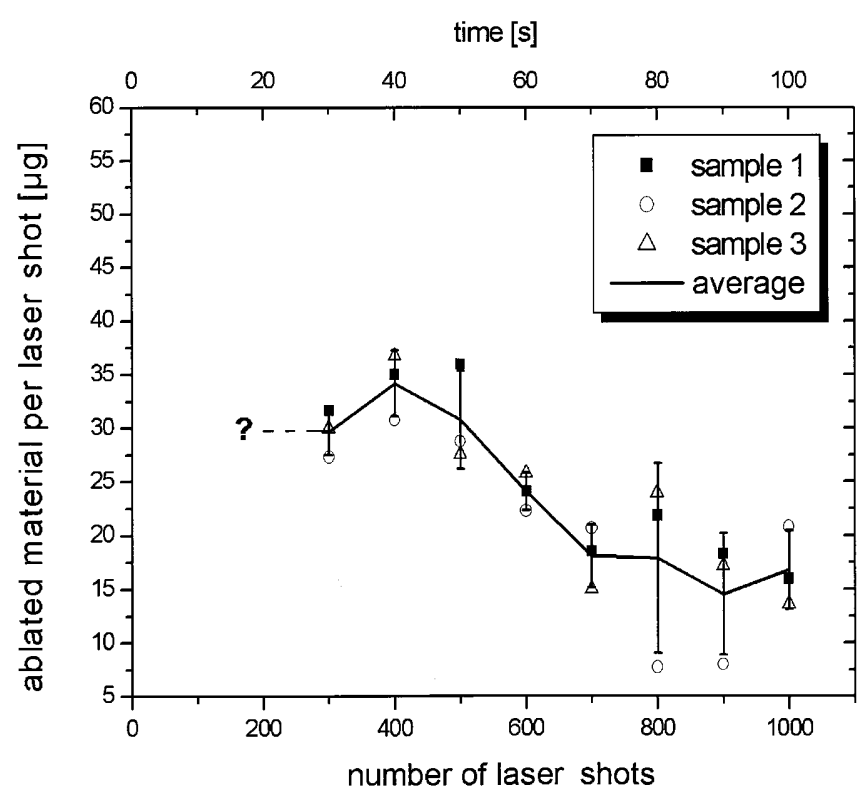

Fig.5 Ablated material per laser shot as a function of measured time 


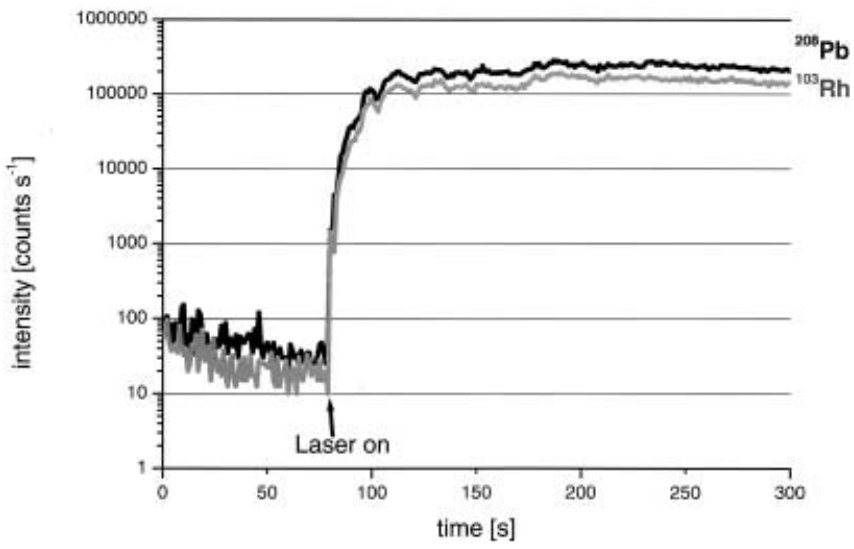

Fig. $6{ }^{208} \mathrm{~Pb}$ and ${ }^{103} \mathrm{Rh}$ signal progressions of a $10 \mu \mathrm{gkg}^{-1}$ ice standard during a line scan

terial from the surface and penetrates deeper into the sample. Thus, the energy of the beam decreases at the surface (defocusing) and less material is ablated. The mass of ablated ice material was measured with an accurate microgram balance after varying numbers of laser shots. A threefold determination of the ablated mass of an ice standard is shown in Fig. 5. After a point scan of $40 \mathrm{~s}$ with a laser energy of $280 \mathrm{~mJ}$ the volume obviously decreases. It was not possible to measure the ice mass removed with fewer than 300 laser shots because the mass was too small for an accurate determination. In the first 40-60 s the removal of material from the ice surface seems to be approximately $30 \mu \mathrm{g}$ per laser shot. The decrease of the removal could also be observed in the loss of signal intensity during ICPMS analysis. For that reason, the line-scan mode was used for calibration studies.

\section{Signal progression}

${ }^{208} \mathrm{~Pb}$ and ${ }^{103} \mathrm{Rh}$ signal progressions of a $10 \mu \mathrm{gkg}^{-1}$ ice standard are demonstrated in Fig. 6. After a short forerun of about $30 \mathrm{~s}$ the signal becomes stable and can be used for measurements. A defined line on the sample surface is scanned several times in line mode. The focus of the laser beam is directed towards the sample surface. Preliminary investigations have shown that, for example, a $10 \mathrm{ngkg}^{-1}$ ice standard signal can still be distinguished very well from the signal of a blank [18]. For a concentration of $10 \mu \mathrm{gkg}^{-1}$ ${ }^{208} \mathrm{~Pb}$ a maximum signal intensity of about $200,000 \mathrm{cps}$ and for ${ }^{103} \mathrm{Rh} 100,000 \mathrm{cps}$ under optimized conditions (Tables $1,2)$ could be reached. Owing to the relatively large dimension of the LA chamber, the wash-out time is about $7 \mathrm{~min}$, depending on the standard concentration.

Calibration studies

Calibration graphs

For several elements which are of interest in natural ice samples calibrations were performed. The results for $\mathrm{Na}$
Table 4 Coefficients of correlation for the calibration of ice standards with a range of $0.01-100 \mu \mathrm{gkg}^{-1}$

\begin{tabular}{lllc}
\hline Isotope & $\begin{array}{l}\text { Correlation } \\
\text { coefficient }\end{array}$ & $\begin{array}{l}\text { Smallest concentration } \\
\text { of standards }\left(\mu \mathrm{kg}^{-1}\right)\end{array}$ & $\begin{array}{l}\text { Number of } \\
\text { standards used }\end{array}$ \\
\hline${ }^{23} \mathrm{Na}$ & 0.999 & 5 & 5 \\
${ }^{24} \mathrm{Mg}$ & 0.999 & 0.05 & 9 \\
${ }^{27} \mathrm{Al}$ & 0.998 & 0.01 & 10 \\
${ }^{43} \mathrm{Ca}$ & 0.845 & 10 & 4 \\
${ }^{44} \mathrm{Ca}$ & 0.935 & 10 & 4 \\
${ }^{56} \mathrm{Fe}$ & 0.981 & 5 & 5 \\
${ }^{57} \mathrm{Fe}$ & 0.996 & 5 & 5 \\
${ }^{64} \mathrm{Zn}$ & 0.999 & 0.01 & 10 \\
${ }^{114} \mathrm{Cd}$ & 0.999 & 0.01 & 10 \\
${ }^{139} \mathrm{La}$ & 1 & 0.01 & 10 \\
${ }^{140} \mathrm{Ce}$ & 1 & 0.01 & 10 \\
${ }^{141} \mathrm{Pr}$ & 1 & 0.01 & 10 \\
${ }^{142} \mathrm{Nd}$ & 1 & 0.01 & 10 \\
${ }^{232} \mathrm{Th}$ & 1 & 0.01 & 10 \\
${ }^{238} \mathrm{U}$ & 1 & 0.01 & 10 \\
${ }^{208} \mathrm{~Pb}$ & 0.999 & 0.01 & \\
\hline
\end{tabular}

and $\mathrm{Mg}$ as tracers for sea salt, $\mathrm{Al}, \mathrm{Fe}$ and some REE as tracers for mineral dust as well as $\mathrm{Zn}$ and $\mathrm{Pb}$ as tracers for anthropogenic sources or contaminations are shown in Table 4. In addition also $\mathrm{Ca}$, which is normally used by glaciologists (analyzed by continuous flow measurements or ion chromatography) as a tracer for dust particles, was calibrated. Calibrations were performed with ten standards in a concentration range from $10 \mathrm{ngkg}^{-1}$ to $100 \mu \mathrm{gkg}^{-1}$. The resulting regression coefficients were found to be between 0.996 and 0.999, except for $\mathrm{Ca} . \mathrm{Na}, \mathrm{Ca}$ and $\mathrm{Fe}$ are difficult to calibrate over the whole concentration range. Here, the less concentrated ice standards yielded very unstable signals and no linear dependency was obtained. The relatively high signals of ${ }^{23} \mathrm{Na},{ }^{44} \mathrm{Ca}$ and ${ }^{56} \mathrm{Fe}$ (strong overlap with ${ }^{40} \mathrm{Ar}^{16} \mathrm{O}$ ) in the blank and the low concentration standards inhibit a calibration at the nanogram per kilogram level. The REE could be calibrated over the whole calibration range with good linear dependence $(R=1)$. To validate the quality of the calibration a frozen standard

Table 5 Analysis of frozen standard reference material NIST $1643 \mathrm{~d}$ (trace elements in water)

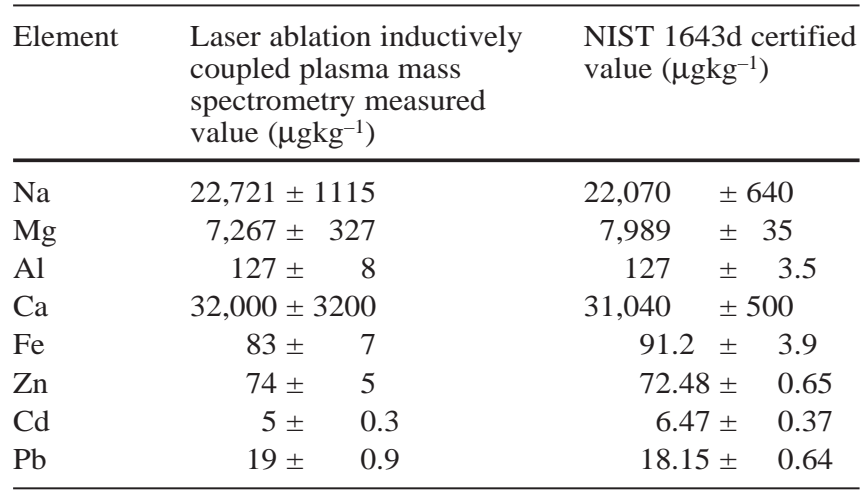


Table 6 Limits of detection ( $3 \sigma$ criteria) as derived from solution nebulization using a cross-flow nebulizer and the MCN 6000 (Cetac Technologies) and in solid ice using laser ablation. The limits of detection are given in micrograms per kilogram

\begin{tabular}{llll}
\hline Isotope & $\begin{array}{l}\text { Laser ablation } \\
\text { Nd:YAG 1064 } \mathrm{nm}\end{array}$ & \multicolumn{2}{l}{ Solution nebulization } \\
\cline { 3 - 4 } & & Cross-flow & MCN 6000 \\
\hline${ }^{23} \mathrm{Na}$ & 0.59 & 1.63 & 0.02 \\
${ }^{24} \mathrm{Mg}$ & 0.05 & 0.04 & 0.01 \\
${ }^{27} \mathrm{Al}$ & 0.18 & 0.06 & 0.05 \\
${ }^{43} \mathrm{Ca}$ & 2.30 & 0.51 & 0.83 \\
${ }^{44} \mathrm{Ca}$ & 19.57 & 3.93 & 0.81 \\
${ }^{56} \mathrm{Fe}$ & 0.70 & - & 0.03 \\
${ }^{64} \mathrm{Zn}$ & 0.06 & 2.19 & 0.02 \\
${ }^{114} \mathrm{Cd}$ & 0.02 & 0.04 & 0.04 \\
${ }^{139} \mathrm{La}^{\mathrm{a}}$ & 3 & 0.5 & 0.9 \\
${ }^{140} \mathrm{Ce} \mathrm{a}^{\mathrm{a}}$ & 4 & 0.2 & 2 \\
${ }^{141} \mathrm{Pr}^{\mathrm{a}}$ & 1 & 0.2 & 1.4 \\
${ }^{142} \mathrm{Nd}^{\mathrm{a}}$ & 2 & 0.6 & 1.1 \\
${ }^{232} \mathrm{Th}^{\mathrm{a}}$ & 1 & 1.8 & 1.1 \\
${ }^{238} \mathrm{U}^{\mathrm{a}}$ & 1 & 0.3 & 1.1 \\
${ }^{208} \mathrm{~Pb}^{24}$ & 0.02 & 0.04 & 0.02 \\
\hline
\end{tabular}

${ }^{a}$ Concentrations given in $\mathrm{ng} \mathrm{kg}^{-1}$

reference material NIST 1643d (trace elements in water) was analyzed as a probe against the calibration curves. The measured concentrations are listed in comparison with the certified values of NIST $1643 \mathrm{~d}$ in Table 5.

\section{Detection limits}

The calculated detection limits ( $3 \sigma$ criteria) which can be obtained in ice core analytics by different sample introduction systems are summarized in Table 6 . It can be seen that the detection limits achieved by LA-ICP-MS measurements are very good taking into account that they are obtained directly from the solid sample. The detection limits for REE achieved with LA-ICP-MS in ice samples are comparable with those from solution nebulization. The values are between 0.001 and $0.01 \mu \mathrm{gkg}^{-1}$.

\section{Internal standard}

As known from solution ICP-MS, the use of an internal standard such as rhodium is important to reduce the influence of signal variations originating from the drift of the ICP-MS signal. In real ice samples there is no possibility to spike the sample. The main reasons for the relatively high signal variations are inhomogeneities of the ice standards and a different removal of material from the ice surface owing to unevenness of the ice or fluctuations in laser energy. In order to avoid such variations in the amount of the ablated sample mass internal standardization is necessary. ${ }^{17} \mathrm{OH}$ and ${ }^{19} \mathrm{OH}$ derived from the ice were chosen for internal standardization [18].

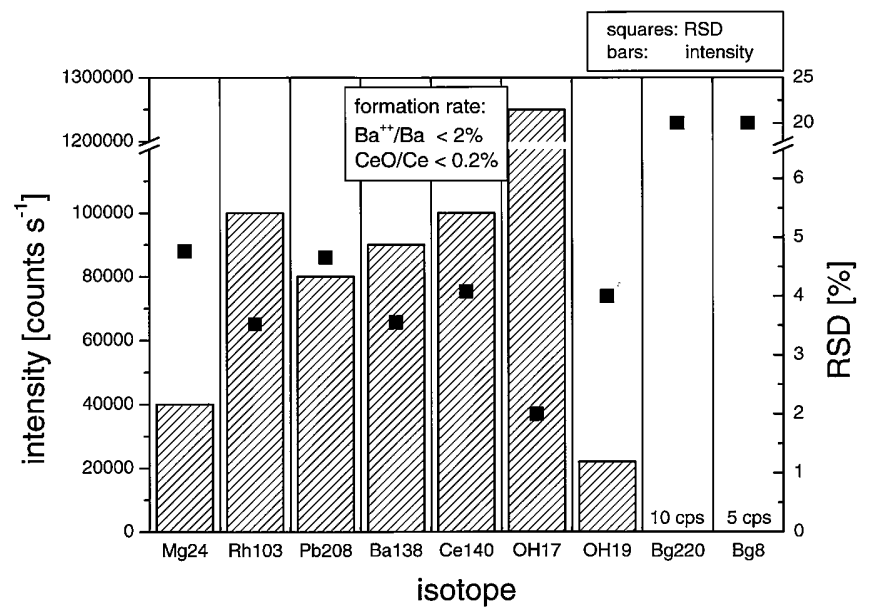

Fig. 7 Signal intensities (bars) and relative standard deviations (RSDs) (squares) of a special $10 \mu \mathrm{gkg}^{-1}$ daily performance ice standard. To check the performance of the laser ablation inductively coupled plasma mass spectrometry system a special number of isotopes are measured

Daily performance ice standard

It is useful to prepare a frozen daily performance standard with a selected content of elements to check the performance of the measurement devices as is also done for solution nebulization. Signal intensities of some isotopes are viewed to check the sensitivity at low, medium and high masses $\left({ }^{24} \mathrm{Mg},{ }^{103} \mathrm{Rh},{ }^{208} \mathrm{~Pb}\right)$ and to control the formation of oxides (formation ratio: ${ }^{140} \mathrm{Ce}^{16} \mathrm{O} /{ }^{140} \mathrm{Ce}$ ) and doubly charged ions (formation ratio: ${ }^{69} \mathrm{Ba}^{2+} / 138 \mathrm{Ba}$ ) by adjusting the operation parameters. In addition, signal intensities and relative standard deviations (RSDs) of the internal standards $\left({ }^{17} \mathrm{OH}\right.$ and $\left.{ }^{19} \mathrm{OH}\right)$ are viewed to check their sensitivity and signal variations. The intensities (bars), RSDs (squares) and the formation ratio (box) of oxides and doubly charged ions of a $10 \mu \mathrm{gkg}^{-1}$ daily performance ice standard are illustrated in Fig. 7. The RSDs are in the range of about 3$6 \%$ (squares). The number of repetition measurements was 6. Owing to a relatively dry laser aerosol the oxide rate was less than $0.2 \%$; the number of doubly charged ions was below $2 \%$. Repeated scanning of a daily performance ice standard provided identical results, indicating the good reproducibility of the method.

\section{Background noise}

Generally, aerosols which are produced by LA are dry and lead to an increased background noise at mass 220. It seems that especially by the use of ELAN 6000 a dry aerosol leads to higher background noise but it is not a problem of the detector. During LA of ice samples, argon, which is used as carrier gas, seems to take up water vapor from the probe. A comparison of different sample introduction systems shows a background of 5-40 cps for the laser and, hence, the values are below the ones produced by an MCN 6000 (Cetac) microconcentric nebulizer (60-100 


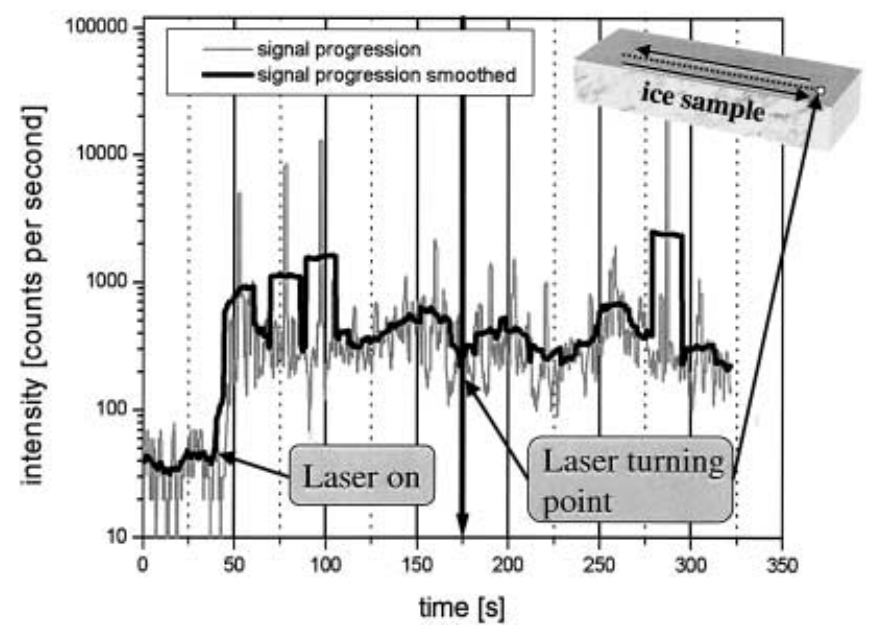

Fig. $8{ }^{208} \mathrm{~Pb}$ signal progression of a real ice sample (Greenland)

cps). On the other hand, results obtained from a cross-flow nebulizer are drastically lower (1-3 cps); therefore, the relatively low background noise caused by the laser aerosol shows a positive effect on the detection limits. According to the alignment of the microconcentric nebulizer a plasma power of $1300 \mathrm{~W}$ was chosen for the laser aerosol.

${ }^{208} \mathrm{~Pb}$ signal progression of a real sample

The signal progression of an analyzed ice core sample segment is shown in Fig. 8. The sample is from Greenland (GRIP) from a depth of $1,100 \mathrm{~m}$ and is about 8,000 years old. After $40 \mathrm{~s}$ of forerun the laser began to fire along a defined line. At the end of the sample $(6 \mathrm{~cm})$, the laser turns and scans back along the same line. The solid line shows the smoothed signal progression of lead. Similar signatures were obtained for the move forwards and backwards along the line scan of the laser. A calculation of the concentrations with the help of the calibration graph for lead results in 10-20 $\mathrm{ngkg}^{-1}$ for the sample. The expected concentration for lead at this depth is about $1-2 \mathrm{ngkg}^{-1}$. This is lower by a factor of 10 ; however, one has to take into account that the values given in Table 3 are averaged over a long time period. This measured ice core sample, however, is only a little piece of the puzzle. It is difficult to compare the data obtained from the sample with those from other methods, for example, solution nebulization ICPMS because the achievable resolution from a molten sample is insufficient to analyze such element signatures. Furthermore, insoluble particles cannot be analyzed in a molten ice sample and pretreatment with decomposition procedures leads to contamination problems. For $\mathrm{Al}$ as a tracer for mineral dust an average of $32 \mu \mathrm{gkg}^{-1}$ (with a range from 1 to $100 \mu \mathrm{gkg}^{-1}$ ) was measured, which is in a good agreement with data from Hong et al. [12], where a concentration range from 5 to $44 \mu \mathrm{gkg}^{-1}$ was analyzed for this depth. $\mathrm{Na}$ as a tracer for sea salt measured by LA-ICP-MS shows an average value of $21 \mu \mathrm{gkg}^{-1}$ with a range from 10 to $150 \mu \mathrm{gkg}^{-1}$. For this time period Na concentrations were measured in a range from 10 to $60 \mu \mathrm{gkg}^{-1}$ by De Angelis et al. [19].

Cryo-SEM photo of particles in an arctic ice core

Along a line scan the laser beam vaporizes small inclusions of particles together with the surrounding ice. Thus, trace element analysis in ice cores represents an integrated signal of elements which are disolved in ice as well as particles incorporated in the ice. Such particles are exemplarily shown for a glacier ice sample from the high Arctic at Spitsbergen $\left(79^{\circ} \mathrm{N}, 12^{\circ} \mathrm{E}\right)$ as well as for the 8,000-yearold Greenland (GRIP) sample in Fig. 9. These particles were identified by EDXA.
Fig. 9 Particles $\left(20 \mu \mathrm{m}_{\circ}\right)$ in glacier ice from Spitsbergen, Ny Ålesund, position $78.9^{\circ} \mathrm{N}, 11.9^{\circ} \mathrm{O}$, as well as in an 8000-year-old ice core sample (depth: $1100 \mathrm{~m}$ ) from Greenland (GRIP)

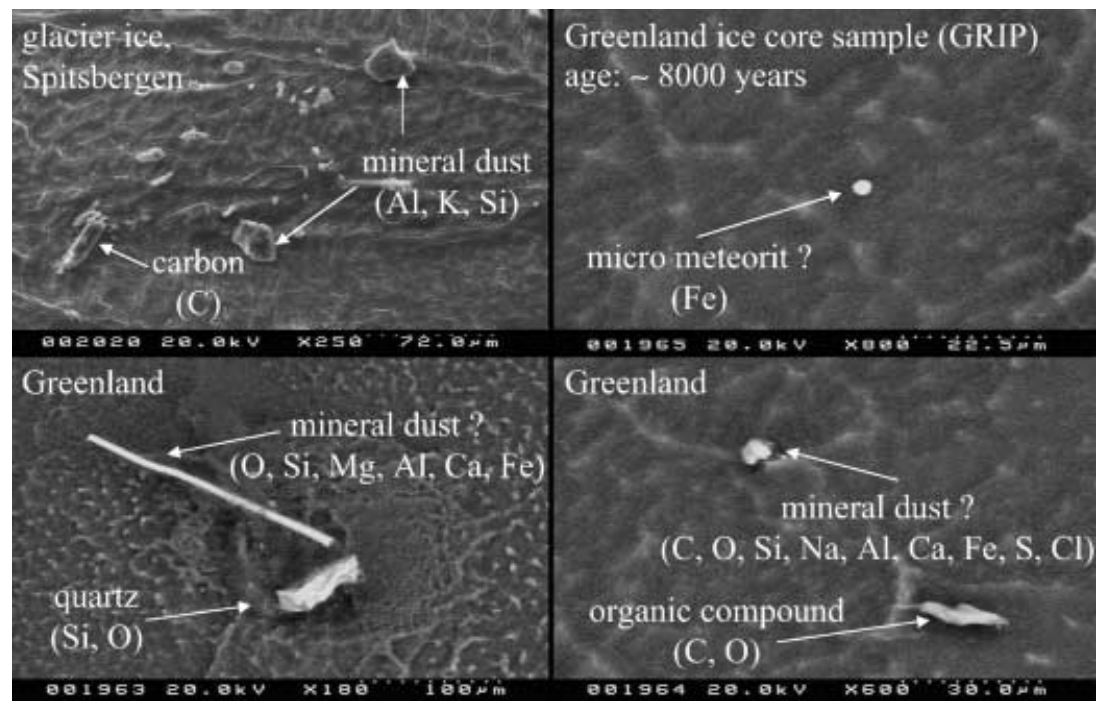




\section{Discussion and outlook}

Preliminary results for direct measurements of frozen ice samples by LA-ICP-MS have shown high counting rates and stable signals. For all interesting elements a successful calibration of ice standards could be achieved. The data gave promising indications that element signatures in annual layers of polar ice cores could be obtained. For the elements $\mathrm{Na}, \mathrm{Ca}$ and $\mathrm{Fe}$ a calibration at the nanogram per kilogram level was not possible because high signal intensities in the blank and the low concentration standards inhibit a calibration at the nanogram per kilogram level.

The achievable resolution depends on the crater size. As reported here, a spot size of about $300 \mu \mathrm{m}$ was obtained during a line scan. This means an considerable improvement in spatial and time resolution in comparison to solution analysis. Kriews et al. [3] obtained element signatures of ice core solutions (NGT08 and B29, Greenland) with an MCN 6000 with a resolution of $25 \mathrm{~cm}$ (NGT08, age 30 years) and $10 \mathrm{~cm}$ (B29, 600 years old). An improvement in resolution will bring more detailed information of element signatures also in low-lying ice layers. With the LA-ICP-MS technique it is possible to measure the whole mass spectrum within a short time; however, one has to take into account that the record of a depth profile with a LA line scan is a time-dependent signal. With scanning quadrupole ICP-MS the achievable resolution does not only depend on the crater spot size of the laser beam but also on the number of measured isotopes. If more isotopes are measured, the time per mass sweep increases and the spatial resolution of the ice sample during a line scan decreases.

In comparison to a cross-flow nebulizer the counting rates are lower by a factor of 3 ; however, the measurement with LA-ICP-MS can be performed directly from the solid sample, which is an enormous advantage. Uncertainties in quantification of the elements are due to the inhomogeneities in the ice standards. In spite of the special sample preparation the freezing process of the standard solutions is the main cause for inhomogeneities inside the ice standards and leads, therefore, to variations of the analyte signal with RSDs of about $5 \%$.

In the future this new technique will be used in our laboratories for natural ice samples from the high Arctic (Greenland, Spitsbergen), Antarctica and sea ice. The coupling of the laser to a time-of-flight ICP mass spectrometer will most likely bring more information on the transient laser signal and a reduction in standard deviations. Furthermore, the application of our newly developed cryogenic ablation chamber for the analysis of biological samples (thin layer of tissue samples) will be investigated for materials of pharmaceutical and medical interest as well as other frozen materials.

Acknowledgements We would like to thank H. Juling for operating the Cryo-SEM and for EDXA at the Materialprüfungsanstalt Bremen. We are also grateful to E. Dunker and I. Beninga for the design and the construction of the cryogenic ablation chamber.

\section{References}

1. Boutron CF, Hong S, Candelone JP (1995) In: Wilken R-D, Förstner U, Knöchel A (eds) Proceedings of the International Conference: Heavy metals in the environment, vol 1. CEP Consultants, Edinburgh, p 28

2. Legrand M, Delmas R (1994) In: Boutron CF (ed) Topics in atmospheric and interstellar physics and chemistry. Les Editions de Physique, Les Ulis, p 387

3. Kriews M, Stölting I, Kipfstuhl J, Schrems O (1998) In: Proceedings of the 4th Symposium Massenspektrometrische Verfahren der Elementspurenanalyse. Poster presentation, Mainz, p 10

4. Matoba S, Nishikawa M, Watanabe O, Fujii Y (1998) J Environ Chem 8:421

5. Palais JM, Kirchner S, Delmas RJ (1990) Ann Glaciol 14:216

6.Zielinski GA, Mayewski PA, Meeker LD, Grönvold K, Twickler MS, Taylor K (1997) J Geophys Res 102:26625

7.Zielinski GA, Germani MS (1998) J Archaeol Sci 25:279

8. Günther D, Jackson SE, Longerich HP (1999) Spectrochim Acta Part B 54:381

9. Warren SG (1984) Appl Opt 23:1206

10. Kriews M, Reinhardt H, Beninga I, Dunker E, Hoffmann E, Lüdke C (1999) German patent application DE 19934561.9-52

11. Candelone JP, Hong S, Pellone C, Boutron CF (1995) J Geophys Res 100:16605-16616

12. Hong S, Candelone JP, Turetta C, Boutron CF (1996) Earth Planet Sci Lett 143:233-244

13. Kriews M, Giese H, Schrems O (1995) In: Welz B (ed) Colloquium Analytische Atomspektroskopie (CANAS'95). PerkinElmer, Überlingen, p 521-529

14. Boutron CF, Candelone JP, Hong S (1994) Geochim Cosmochim Acta 58:3217-3225

15. Spiricon Inc. (1998) Model LBA-300PC laser beam analyser for Windows 95/98/NT

16. Langenfeld M, Kaiser P, Juling H, Blaschke R (1994) In: Tagungsband der 16. Vortragsveranstaltung des Arbeitskreises Rastermikroskopie in der Materialprüfung des DVM in Dresden. Deutscher Verband für Materialforschung und Prüfung e.V., Berlin, p 261-266

17. Langenfeld M, Juling H, Blaschke R (1994) Wiss Z Hochsch Archit Bauwes 40:23-26

18. Reinhardt H, Kriews M, Schrems O, Lüdke C, Hoffmann E, Skole J (2001) In: Holland G, Tanner D (eds) Plasma source mass spectrometry: the new millennium. The Royal Society of Chemistry, Cambridge, pp 185-194

19. De Angelis M, Steffensen JP, Legrand M, Clausen H, Hammer C (1997) J Geophys Res 102:26681-26698 